\title{
The Construction Strategies of the Synergy Mechanism of Production and Education Integration in Applied Undergraduate Colleges
}

\author{
Junzheng Wu \\ Xi’an Peihua University, Xi’an, Shannxi, 710125, China
}

Keywords: Applied Undergraduate Colleges; Production and Education Integration; Synergy Mechanism; Construction Strategy

\begin{abstract}
Constructing the synergy mechanism of production and education integration is not only the internal requirement of the transformation from local undergraduate colleges to applied universities, but also the need of the sustainable development of engineering enterprises under the market economy environment. Based on the author's learning and practical experience, this paper first analyzed the basic problems of the synergy mechanism of production and education integration, then put forward the construction strategies of synergy mechanism of production and education integration in applied undergraduate colleges. Based on the practice of school-enterprise cooperation personnel training model, this paper discussed a new mode of cultivating talents in applied undergraduate colleges, which will provide a certain reference in order to promote the transformation and development of local colleges.
\end{abstract}

\section{Introduction}

At present, some important problems in the field of talent training in applied local undergraduate colleges are that there is a clear gap between the demand of the students and the society, the social responsibility of the graduates is deficient, and the innovation spiri and the practical ability are weak. These problems lead to the quality of talent training can not meet the requirements of regional economic and social development. Many local colleges and universities at home and abroad are looking for a new model of talent training suitable for their own characteristics. According to the decision and arrangement made by the CPC Central Committee and the State Council to guide some local colleges and universities to change to application type, it is the primary problem to adapt to the synergy mechanism of production and education integration under the new situation.

\section{The Basic Problems in the Synergy Mechanism of Production and Education Integration}

\subsection{The connotation of synergy mechanism of production and education integration.}

Production and education integration is a new way of education. Institutions of higher learning, government, enterprises and scientific research institutions give full play to their resources and advantages based on mutual trust and contracts, to take meeting market needs as their starting point. As one of the core concepts of collaborative innovation, synergy mechanism refers to the effective interaction and synergy effect of resource sharing and accumulation of energy in the cooperative system. Synergy mechanism of production and education integration is a highlight of higher education reform, and it is also the innovative practice of cultivating talents in colleges and universities.

\subsection{The basis of the synergy mechanism of production and education integration.}

(1) Theoretical basis. Synergy theory, system theory and integration theory are the main theoretical basis for the integration of production and education. Synergy theory holds that the result of synergy is to benefit individual elements and strengthen the overall benefit. System theory holds that any system is an organic whole, and its function is greater than the sum of the functions 
of each part. By reorganizing and integrating the sub-elements of the system, the theory of integration makes it form a reasonable structure, realize the overall optimization and coordinated development, and maximize the function and benefit of the whole. (2) Realistic basis. First, state policy. Decision of the CPC Central Committee on comprehensively deepening the Reform, Decision of the State Council on Speeding up the Development of Modern Vocational Education, Planning for the Construction of the Modern Vocational Education system (2014-2020) and Some Opinions on Improving the Quality of Higher Education in an All-round Way, these documents all propose that the integration of industry and education should be adopted to achieve the goal of cultivating applied talents. In addition, some local governments, such as Shanghai, Dalian, Suzhou and Ningbo, have issued a series of documents to encourage the integration of industry and education, which has played a positive role in promoting the integration of industry and education. Second, the current situation of talent training in private colleges and universities. Through investigation and analysis of literature, we find that there are the following problems in the integration of industry and education in private colleges and universities: The concept of "synergy" has not yet penetrated into the thought of personnel training in private colleges and Universities; The goal of cultivating applied talents put forward by private colleges and universities converges; Teachers lack practical experience; the professional setting of private colleges and universities, curriculum structure and teaching content have not been effectively docked with the integration of production and education; The teaching management is not flexible enough, and the evaluation standard system of talent training quality is not perfect enough. Therefore, it is necessary to construct the talent training model and synergy mechanism of production and education integration.

\section{The Construction Strategies of the Synergy Mechanism of Production and Education Integration}

\subsection{Government coordination and legal restraint mechanisms.}

The government should take the lead to construct the public network information platform of the cooperation between school and enterprise, to reduce the asymmetry of information between school and enterprise, and to realize the sharing of information resources. Set up committee and expert pool to realize the transform of the government and industry enterprises in the integration of industry and education from the object of cooperation to the main body of cooperation. Through the function of information exchange, communication and cooperation, the special advantages of the committee and its members in the professional field can be brought into full play, and the convenient channel for the integration of industry and education can be set up effectively. The government should establish a rigid legal and regulatory restraint mechanism, clarify the relationship between the rights and obligations of each partner, and even stipulate the liability for breach of contract. The government should introduce preferential policies to mobilize the enthusiasm of both the industry and the teachers to cooperate in educating people. The government should coordinate the resources of universities and enterprises, determine the strategic direction and objectives, study the policies and measures of the integration of industry and education, solve the difficulties that cannot be solved by both sides in the cooperation of production and education, and ensure that the related activities are carried out in an orderly manner.

\subsection{Good operating mechanism in and out of school.}

(1) Innovation of school running mode. Adhering to the development concept of cooperation between schools and enterprises and integration of industry and education, relying on the cooperation between schools and enterprises and employment guidance centers, teaching units, science and research departments and other departments, we can strengthen cooperation with the government, industry and enterprises, to explor the Mode of "Cooperation of Government, School, Enterprise". The cooperative education steering committee should be formed as the main body, the function department as the main body, the teaching department as the main body, and the teaching department as the main body to carry out the management structure of the cooperation between the 
school and the enterprise, so as to jointly promote the integration of production and education. (2) Joint-stock cooperation and enterprise operation. Cooperation between schools and enterprises can apply for provincial science and technology start-up parks to incubate enterprises, technology, talents, to provide students with entrepreneurial and employment opportunities, to promote the transformation of teachers' scientific research achievements and serve the local economic development. Through the deep cooperation between the school and the enterprise, the development pattern of "innovation in the campus, entrepreneurship in the park, and industrial development in the industrial park" is formed, which makes outstanding contributions to the development of regional economy and society.

\subsection{Innovative mechanisms for integrating production and education}

Institutions of higher learning and governments, colleges, industries and enterprises can jointly establish industrial colleges of mixed ownership, targeted training classes, college students' Innovation and Entrepreneurship Center, training organization to form five modes of cooperation between schools and enterprises, with the integration of production and teaching, the practice of modern apprenticeship, the alternation of work and learning, the development and service of technology, and the training of technical skills. At the same time, it is necessary to put into practice advanced concepts such as mixed ownership, modern apprenticeship, combination of work and study, integration of production and teaching, etc.

\subsection{To promote the co-education and to establish a joint production and research platform.}

The cultivation of "double teachers and abilities" is an important way to promote the integration of industry and teaching in local colleges and universities. Teachers' practical ability, teaching and scientific research level directly affect the quality of students' training. The school should educate the teachers with "double teachers and abilities" through the integration of production and education with enterprises and industries. First of all, according to the different curriculum and teaching plan arrangements undertaken by the teachers, local colleges and universities adopt a classification of training. The young teachers should be assigned to the construction site or the practical teaching base in the school, and be directed by the engineering enterprise to train the teachers' practical operation ability and technical application ability. Through engineering practice, these teachers can not only understand the latest trends and development direction of the relevant major, but also bring the project into the teaching and make the classroom teaching around the real cases, which makes the teaching content more close to the engineering practice. At the same time, it can also solve the problems - the integration of scientific research results with the market is not close, and the conversion rate of achievements is low. Secondly, local colleges and universities regularly employ professional and technical staff from the joint venture as part-time teachers, and the school organizes short-term education and teaching ability training, school management system and cultural training, to enable enterprise engineers to have the basic educational and teaching ability. Third, sharing school and enterprise resources, building engineering center, technology research center and other institutions, forming resources integration and sharing. Through the cooperation between university teachers and enterprise engineers, the bottleneck faced by engineering enterprises in technological and scientific innovation can be solved, and more technical support will be provided for the innovation of enterprises; Through the cooperation between enterprises and schools, it can realize the common innovation of scientific research and development, so it will form a new mode of resource sharing, achievement sharing and win-win benefit, and thus to establish a long-term cooperation mechanism.

Improve multiple assessment and oversight mechanisms. (1) Competency-based evaluation mechanism. To formulate the "ability-based" assessment goals and systems can make a comprehensive assessment for students' comprehensive ability. Carry out the multi-subject evaluation model combining school, enterprise and social evaluation, and actively explore the introduction of third party to complete the evaluation, using written test, oral test, paper, operation, work presentation and research results and other evaluation methods. (2) The teaching co-management mechanism. It is implemented from the following aspects: First of all, the 
introduction of fine teaching management. We can use the "rolling plan" and "horizontal chart" to break down the long-term, medium-term and short-term goals of talent training. Teachers' teaching plans, handouts, courseware and other teaching documents are well prepared and reviewed by experts in schools and enterprises. The enterprise arranges personnel to follow up and check the implementation of the teaching and put it on record, so as to ensure the teaching effect. (3) Support service mechanism. It requires annual working meetings involving governments, schools and businesses to absorb industry experts as members of professional construction guidance organizations. Schools need to be subject to industry inspection and guidance in the aspects of talent training objectives and programs, professional construction, teacher team building, quality evaluation, etc.

\section{Conclusions}

The talent training model based on production and education integration has been successfully applied in some universities at home and abroad. However, due to the lack of national system protection, the lack of enthusiasm of enterprises, the lack of attractive school conditions and other factors, the synergy mechanism of production and education integration in some colleges and universities is still in a shallow level, and has not yet formed a scientific and deep cooperation system. How to deepen the production and education integration, we must find out the balance of interests between school and enterprise. Only by realizing the mutual benefit between school and enterprise, can we establish a long-term mechanism of production and education integration.

\section{References}

[1] Wang Shuzhang, Lu Yijun. Construction of Modern higher Vocational Education system under the background of Integration of Industry and Education [J]. Research on higher engineering education, 2016, (04): 155-159.

[2] Wang Jian, $\mathrm{Xu}$ Xiuqing, Zhan Youji. Integration of production and teaching: the only way to train high-quality applied talents [J]. Science and Technology in China's Colleges and Universities, 2016, (07): 55-57.

[3] Zou Songlin. Study on the construction path of ecosphere of production and education integration [D]. Jiangxi Agricultural University.

[4] Chen Nianyou, Zhou Changqing. The connotation and realization of the integration of industry and education [J]. University Science and Technology in China 2014, (08): 40-42. 